\title{
Open Seldinger-guided peripheral femoro- femoral cannulation technique for totally endoscopic cardiac surgery
}

\author{
Yi Chen ${ }^{1,2}$, Liang-wan Chen ${ }^{1}$, Xiao-fu Dai ${ }^{1}$ and Xue-shan Huang ${ }^{1,2^{*}}$
}

\begin{abstract}
Background: The cannulation technique used in totally endoscopic cardiac surgery has a significant impact on the overall prognosis of patients. However, there are no large cohort studies to discuss it. Here we report on our research of using open Seldinger-guided technique to establish femoro-femoral cardiopulmonary bypass during totally endoscopic cardiac surgery and evaluate its safety and efficacy.

Methods: The institutional database from 2017 to 2020 was retrospectively reviewed to find cases in which totally endoscopic cardiac surgery was performed. We identified 214 consecutive patients who underwent totally endoscopic cardiac surgery with peripheral femoro-femoral cannulation. All patients underwent femoral artery cannulation. Of these, 201 were cannulated in the femoral vein and 13 were cannulated in the femoral vein combined with internal jugular cannulation. The technique involves surgically exposing the femoral vessel, setting up purse-string over the vessels and then inserting a guidewire into the femoral vessel without a vascular incision, followed by exchange of the guidewire with a cannula.
\end{abstract}

Results: Surgery indications included mitral valve disease in $82.71 \%(177 / 214)$, atrial septal defect in 11.68\% (25/214) and tricuspid regurgitation in the remaining 5.61\% (12/214). Hospital survival was 98.60\% (211/214). There were no cases of stroke and postoperative limb ischaemia. No femoral vessel injuries or wound infections was observed. No late pseudoaneurysms were evident.

Conclusion: The open Seldinger-guided femoro-femoral cannulation technique is effective and safe. We highly recommend this technique, given its safety, simplicity and speed under direct vision. The limited manipulation of the vessels under direct vision minimizes the risk of local complications.

Keywords: Seldinger-guided technique, Femoro-femoral cannulation, Totally endoscopic

\section{Introduction}

Minimally invasive cardiac surgery (MICS) was successfully introduced since the mid-1990s $[1,2]$. Due to the advantages of more attractive cosmetic results, lower pain levels, less physical trauma and quicker recovery,

\footnotetext{
* Correspondence: 757075427@qq.com

1 Department of Cardiovascular Surgery, Union Hospital, Fujian Medical University, Fuzhou, China

${ }^{2}$ Key Laboratory of Cardio-Thoracic Surgery (Fujian Medical University), Fujian Province University, Fuzhou, China
}

MICS has gradually become more and more popular worldwide [3-6].

Totally endoscopic cardiac surgery is one of the MICS, characterized by the non-disruption of the thoracic structures and the extra-thoracic extracorporeal circulation $[3,7,8]$. Previous studies have confirmed the safety and effectiveness of this procedure [6,9].

In totally endoscopic cardiac surgery, perfusion strategies have a significant impact on the overall prognosis of the patient. It needs to meet the following conditions:

(c) The Author(s). 2021 Open Access This article is licensed under a Creative Commons Attribution 4.0 International License, which permits use, sharing, adaptation, distribution and reproduction in any medium or format, as long as you give appropriate credit to the original author(s) and the source, provide a link to the Creative Commons licence, and indicate if changes were made. The images or other third party material in this article are included in the article's Creative Commons licence, unless indicated otherwise in a credit line to the material. If material is not included in the article's Creative Commons licence and your intended use is not permitted by statutory regulation or exceeds the permitted use, you will need to obtain permission directly from the copyright holder. To view a copy of this licence, visit http://creativecommons.org/licenses/by/4.0/ The Creative Commons Public Domain Dedication waiver (http://creativecommons.org/publicdomain/zero/1.0/) applies to the data made available in this article, unless otherwise stated in a credit line to the data. 
1. The flow should meet the needs of adequate perfusion without increasing neurological complications or vascular injuries; 2 . Can be easily and fast manipulate; 3 . The exposure is satisfied and the intracardiac visual field should not be affected. Besides, it also needs to reduce the risk of limb ischemia [10].

The most common perfusion strategies used during totally endoscopic cardiac surgery was the femorofemoral cardiopulmonary bypass (CPB) in our institution. Open Seldinger-guided peripheral femoral cannulation was routinely used to establish extrathoracic extracorporeal circulation [11].

Currently, the mainstream cannulation technique to establish femoro-femoral CPB included: percutaneous puncture $[12,13]$, traditional vascular cannulation technique [14], and using side-arm graft sewn to the femoral artery for perfusion [15]. To reduce complications related to lower limb ischemia, the bidirectional perfusion cannula has also been developed [16]. However, few literatures have reported on the specific steps of peripheral vascular cannulation to establish femoro-femoral cardiopulmonary bypass.

Our institutional preference is surgical exposure of the femoral vessels and then performed Seldinger-guided femoral artery cannulation [17], with venous drainage from the vena cava by femoral vein cannulation or cannulated in the femoral vein combined with internal jugular cannulation. For this approach, it is a technique that combines operational speed and safe under direct vision with minimal risk. The advantages of this technique are as follows:visibility, simplicity, speed and safe.

Since 2017, the open Seldinger-guided femoro-femoral cannulation has been routinely used in our institution. The aim of our study is to assess the efficacy and safety of this technique.

\section{Materials and methods \\ Patients and methods}

We retrospectively analyzed our institutional dataset from 2017 to 2020 to find all patients who underwent totally endoscopic cardiac surgery. This retrospective analysis was based on data from the Institute of Cardiothoracic Surgery at Fujian Union Hospital. In this study, informed consent was not required as the analysis is conducted using anonymous clinical data from each patient.

Medical records were specifically reviewed for different types of cardiac surgery (atrial septal defect repair, tricuspid valve repair, or mitral valve surgery), site of cannulation (femoral, jugular vein), and reasons for combined cannulation, post-operative data. It also includes demographic data, including gender, age, and body mass index. Special attention is paid to the complications associated with cannulation, including intra- operative arterial and venous injury (vascular rupture or artery dissection), lower limb ischemia, wound infection, hematoma or seroma.

\section{Surgical techniques}

The cannulation procedure has been developed which is designed to combine efficiency and speed with minimal risks. The steps in the procedure include: (I) surgical exposure the femoral vessels; (II) peripheral femorofemoral cannulation by the open Seldinger technique; (III) Transesophageal echocardiography (TEE) guided access and properly positioning of the cannula.

Preoperative examination was carefully performed to rule out possible contraindications such as severe calcifications in descending aorta and iliofemoral artery or patients with inferior vena cava filters or deep venous thrombosis. Femoral artery cannulation cannot be used when there is atherosclerosis or other potential source of embolism in the thoraco-abdominal aorta. Other reasons for not having femoro-femoral cannulation include extreme obesity or peripheral vascular disease of the iliac-femoral vascular system.

Open Seldinger-guided femoro-femoral cannulation was carried out as follows: First a vertical incision is made in the groin, through the inguinal crease. We usually prefer the right side, unless there is evidence of a lesion in the ipsilateral right femoral vessel, in which case we choose the left groin. The surgeons were divided into two groups, one for chest wall ports made and one for femoro-femoral cannulation. Dissecting the subcutaneous tissue to expose the femoral sheath, which was incised longitudinally. Isolated the femoral vessels from the surrounding tissue using a sharp dissection. Two independent purse-string sutures were made on the exposed anterior femoral vessels using 5-0 Prolene. Following administration of heparin, an 18G needle was then inserted into the purse-string, a 0.038-in. guidewire was guided through the needle into the thoracic descending aorta or inferior vena cava under TEE guidance. We use a femoral arterial cannula of $18 \mathrm{Fr}$ to $22 \mathrm{Fr}$ and a single two-stage venous cannula of $24 \mathrm{Fr}$ to $28 \mathrm{Fr}$ (this depends on the patient's weight). This arterial and venous cannula with a tapered tip accommodates the guidewire has a smooth transition from the dilator to the cannula for easy insertion. After removal of the needle, the dilator and the cannula were advanced over the guidewire with the modified Seldinger-technique technique. When correctly positioned under TEE, the internal dilator is removed, the cannula is connected to the arterial circuit and venous circuit and the cannula secured to the snare by cinched the purse-string down. With femoral or combined venous cannulation is performed, femoro-femoral CPB is initiated. After the operation is ended, when the patient is weaned from 
extracorporeal circulation, the cannula was removed, usually by simply tied the purse-string and no clamping the vessel. We routinely made an additional purse-string around the first purse-string to reduce the risk of bleeding. Then check for an arterial pulse at the distal end of the purse-string (Fig. 1).

\section{Definition of clinical parameters}

Mortality was defined as all-cause death less than 30 days after surgery or during hospitalization. Stroke was defined as an acute episode of focal dysfunction of the brain, retina, or spinal cord lasting longer than $24 \mathrm{~h}$, or of any duration if imaging (CT or MRI) or autopsy show focal infarction or haemorrhage relevant to the symptoms $[18,19]$. The definition of acute kidney injury is based on the Kidney Disease Improving Global Outcomes (KDIGO) criteria [20].

\section{Statistical analysis}

SPSS (IBM, Version 24.0) was used for statistical analysis. Normal distribution continuous variables were expressed as the mean \pm standard distribution.

\section{Results}

\section{Patients baseline data}

We collected data on 214 consecutive patients who underwent peripheral femoral cannulation. Mean age of patients was $51.03 \pm 12.29$ (range 23-72) years and $55.61 \%$ (119 of 214) were female. Mean BMI was $24.34 \pm 1.99 \mathrm{~kg} / \mathrm{m}^{2}$. Forty-eight patients $(22.43 \%)$ were diagnosed with hypertension, twenty-eight $(13.08 \%)$ patients with diabetes. The mean LVED was $60.31 \pm 8.43$ $\mathrm{mm}$. The mean LVEF was $53.75 \pm 7.33 \%$. The baseline data are listed in Table 1 . All procedures were electively performed.

\section{Outcomes}

All patients using this technique had successful peripheral cannulation. Femoral artery cannulation was carried out for totally endoscopic cardiac surgery in all patients. Of these, 201 were femoral vein cannulation and 13 were combined venous cannulations. Indications for surgery

Table 1 Baseline data

\begin{tabular}{ll}
\hline Item & Data \\
\hline Male/Female & $95 / 119$ \\
Age (years) & $51.03 \pm 12.29$ \\
BMI $\left(\mathrm{kg} / \mathrm{m}^{2}\right)$ & $24.34 \pm 1.99$ \\
Hypertension $(\mathrm{n}, \%)$ & $48(22.43 \%)$ \\
Diabetes $(\mathrm{n}, \%)$ & $28(13.08 \%)$ \\
LVED $(\mathrm{mm})$ & $60.31 \pm 8.43$ \\
LVEF (\%) & $53.75 \pm 7.33 \%$ \\
\hline
\end{tabular}

included mitral valve disease in $82.71 \%(177 / 214)$, atrial septal defect in $11.68 \%(25 / 214)$ and tricuspid regurgitation in the remaining 5.61\% (12/214). Mean CPB time was $146.32 \pm 31.28$ mins. The detailed operative data are shown in Table 2. The in-hospital survival was $98.60 \%$ (Table 3). One died of renal failure following postoperative hemorrhage and secondary multiple organ failure, and two died of uncontrollable severe pneumonia and sepsis. There were no cases of intra-operative femoral arterial injuries and no dilator-related problems during surgery. There were no recorded cases of postoperative lower limb ischaemia or stroke. No cases of early or late wound infection. Wound seroma happened in only two patients. Only one $(0.47 \%)$ patient showed clinical signs of venous thromboembolism. The femoral vein stenting was successfully performed and the patient was discharged from hospital. There was not a single case of late pseudoaneurysm present at the cannulation site.

\section{Discussion}

Since Mohr and Felger reported the initial successful experience of port-access cardiac surgery. Using singlelung ventilation, with $\mathrm{CPB}$ established through peripheral femoro-femoral cannulation and an endo-aortic balloon catheter for cardioplegia delivery and root deairing. Different minimally invasive surgical approaches allowed heart valve surgery sparing sternal incision [3, 21]. Totally Endoscopic cardiac surgery is gradually popularized worldwide due to the cosmetic benefits of minimally invasive techniques with smaller incisions and faster recovery $[3,5,22]$.

The controversy continues on the optimal cannulation site for totally endoscopic cardiac surgery. Best cannulation strategy for endoscopic surgery has been a topic of debate for nearly two decades. Cannulation technique to establish CPB during endoscopic surgery should be fast and using specific technique that minimizes the tissue trauma which could lead to the risk of reoperation, bleeding and need for blood transfusion. Malpositioned cannula may lead to low $\mathrm{CPB}$ flows, and inadequate drainage. Improper movement of the cannulas or poor secured cannula may lead to catastrophic decannulation. There are various approaches to establish cardiopulmonary bypass for endoscopic surgery. Because totally endoscopic cardiac surgery does not destroy the thoracic structure, extracorporeal circulation can be established through peripheral femoro-femoral cannulation.

Femoral artery cannulation has been routinely used since the early days of minimally invasive port-access mitral valve surgery $[21,23]$. But negative neurocognitive outcomes and retrograde dissection associated with femoral retrograde perfusion has made peripheral approach decreasingly popular in this years [24-26], it finally being replaced by the ascending aorta canulation. This is 


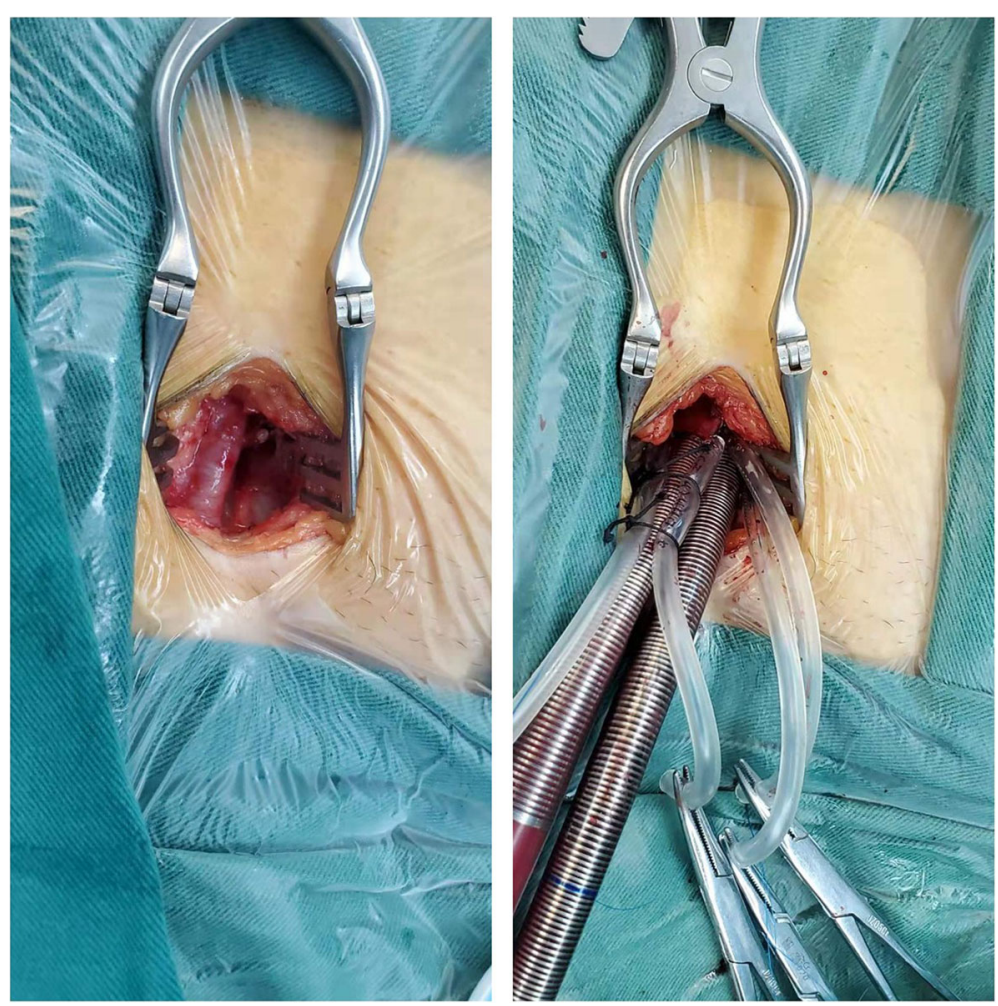

Fig. 1 Surgical exposure and cannulation of femoral vessels

despite the fact that cannulation of the distal ascending aorta is undoubtedly the most expedient and safest site for arterial inflow. However, with considerable advancements in minimally invasive techniques, including remarkable improvements in the quality of cannula and case selection under CT-guided, it seems that the use of retrograde femoral perfusion in totally endoscopic or robotic cardiac surgeries as safe and increasingly routine [27-29].

With the development of large-bore, thin-walled venous cannula with high flow and the improved performance of ultrasound machines have made femoral venous

Table 2 Intra-operative data

\begin{tabular}{ll}
\hline Item & Data \\
\hline Surgery strategy & \\
Mitral valve surgery $(\mathrm{n}, \%)$ & $177(82.71 \%)$ \\
Tricuspid valve surgery $(\mathrm{n}, \%)$ & $12(5.61 \%)$ \\
Atrial septal defect repair $(\mathrm{n}, \%)$ & $25(11.68 \%)$ \\
Cannulation site & \\
Femoral artery & 214 \\
Femoral venous & 201 \\
Combined venous & 13 \\
CPB time (min) & $146.32 \pm 31.28$ \\
\hline
\end{tabular}

cannulation more popular. The single two-stage venous cannula is now selected as our primary choice. If the venous drainage is not smooth, the vacuum-assisted device can be initiated, and the internal jugular vein also can be cannulated during surgery. In addition, combined cannulation can be chosen in patients with interatrial sulcus opening, preoperative ultrasound indicated insufficient venous diameter or in-operative difficult exposure is expected. The literature shows that femoral vein cannulation is also very safe [30].

In our experience, peripheral femoro-femoral cannulation for retrograde perfusion and venous drainage from

Table 3 Postoperative Data

\begin{tabular}{ll}
\hline Item & TA group \\
\hline Mortality & $3(1.40 \%)$ \\
Intensive care unit stay (hours) & $32.13 \pm 18.61$ \\
Stroke $(n, \%)$ & 0 \\
Lower limb ischaemia ( $n, \%)$ & 0 \\
Embolism ( $n, \%)$ & $1(0.47 \%)$ \\
Bleeding events (n, \%) & $2(0.93 \%)$ \\
Groin wound problem (n, \%) & $2(0.93 \%)$ \\
Pneumothorax (n, \%) & $4(1.87 \%)$ \\
Subcutaneous emphysema (n, \%) & $3(1.40 \%)$ \\
\hline
\end{tabular}


the inferior vena cava remains a good option. It needs to follow the below fundamental principles: (1) rapid establishment of CPB and maintenance of adequate perfusion, (2) optimal exposure and make sure the exposure is not affected, and (3) suitable for the patient's pathology. Cannulation under direct vision is simple in anatomy and reduces the risks associated with percutaneous cannulation. These include difficulty in placing large cannulaes, rupture of vessels, and retroperitoneal hematoma. The procedure is simple and fast, and there is no need for complex manipulating of the femoral artery and vein (such as side-arm), and there are few local complications.

Here, we present a description of the experience of 214 consecutive patients who received open Seldingerguided peripheral femoro-femoral cannulation for totally endoscopic cardiac surgery. This technique is rapid and simple, only minimal manipulation and dissection of the femoral vessels is required. Our results strongly support the use of this technology. The overall survival rate of the patients was $98.60 \%$. None of the deaths were associated with femoral vascular cannulation and retrograde perfusion of the femoral artery. This rate is similar with a series of recently published reports [25, 31-33]. In addition, we had no patients with stroke and we found no cases of inadequate CPB flow, aortic dissection or arterial injury. The additional benefit of not requiring an arterial snare, which allows distal limb perfusion, is also supported by our results. No one of lower limb ischemia was identified. Wound seroma happened in only two patients, and our wound complication rate was $0.93 \%$.

The excellent outcome of our peripheral femorofemoral cannulation using the open Seldinger-guided technique has several potential reasons. Firstly, an important adjunct to this is the pre-operative CT scan and the intra-operative use of ultrasound, which allows us to identify patients with iliac and femoral atheromatous plaques, which could potentially mobilize aortic debris to enter the cerebral circulation, which may increase retrograde perfusion cerebrovascular complications. Secondly, the simple manipulation and minimal dissection of the femoral vessels minimize local vascular trauma and reduce perivascular lymphatic destruction, so wound infection and seroma are minimized. Thirdly, the largebore, thin-walled cannula incorporating a tapered tip, which has a smooth dilator-to-cannula transition, not only minimizes the size of the vascular opening but also allows easy insertion with the Seldinger-guided technique, which could be repaired by simply tying the purse-string.

Other forms of femoral artery cannulation that have become quite popular are not without their obvious disadvantages. As it is more time consuming, the use of side-arm grafts is contraindicated. In addition, the side- arm grafts anastomosis is prone to bleed during the CPB. The side-arm must be suture to close at the end of the CPB. The permanent graft will remain in place indefinitely. Peripheral extracorporeal circulation through the femoral vessels is an accepted technique. In contrast, open Seldinger-guided femoral cannulation simply and completely avoids these drawbacks associated with sidearm or incision technique. In the subject of venous cannulation, the single two stage venous cannula can avoid the jugular cannulation. With percutaneous puncture, venous drainage is impeded due to the small size of the cannula. Open Seldinger-guided femoro-femoral technique can avoid these drawbacks.

In discussing the limitations of this research, it is important to indicate that this study is not an attempt to compare different peripheral cannulation techniques. It is a retrospective study that our goals are simply to indicate the efficacy and safety of this technique for peripheral femoral cannulation.

\section{Conclusion}

This study indicates that the open Seldinger-guided femoro-femoral technique for peripheral femoral cannulation is efficient and safe under direct vision and with intra-operative TEE. The surgical trauma of the femoral vessel is minimized. Using the Seldinger-guided technique decreases the manipulate time. Besides, the vessel is not snared, thereby preserving the distal blood flow and reducing the risk of limb ischaemia. We recommend open Seldinger-guided peripheral femoral cannulation for its rapidity, simplicity and effectiveness.

\section{Abbreviations}

MICS: Minimally invasive cardiac surgery; CPB: Cardiopulmonary bypass; TEE: Transesophageal echocardiography

\section{Supplementary Information}

The online version contains supplementary material available at https://doi. org/10.1186/s13019-021-01584-x.

\section{Additional file 1. \\ Additional file 2. \\ Additional file 3. \\ Additional file 4.}

\section{Acknowledgements}

We highly acknowledge the contributions of the participating doctors: Daozhong Chen, Feng Lin, Qi-min Wang, Han-fan Qiu, and Dong-shan Liao.

\section{Authors' contributions \\ Yi Chen and Xue-Shan Huang designed the study, participated in the oper- ation, and drafted the manuscript. Yi Chen collected the clinical data and performed the statistical analysis. Liang-Wang Chen and Xiao-Fu Dai pro- vided technical support. All authors read and approved the final manuscript.}

\section{Funding}

There is no financial support for this work. 


\section{Availability of data and materials}

Data sharing was not applicable to this article, as no data sets were generated or analysed during the current study.

\section{Declarations}

\section{Ethics approval and consent to participate}

This study complied with the requirements of the Ethics Committee of Fujian Medical University and adhered to the Declaration of Helsinki. Informed consent was waived due to the retrospective nature of the study.

\section{Consent for publication}

Not applicable.

\section{Competing interests}

The authors declare that they have no competing interests.

\section{Received: 3 May 2021 Accepted: 10 July 2021}

Published online: 22 July 2021

\section{References}

1. Navia $\mathrm{J}$, Cosgrove DM. Minimally invasive mitral valve operations. Ann Thorac Surg. 1996;62(5):1542-4. https://doi.org/10.1016/0003-4975(96)007795.

2. Cohn LH, Adams DH, Couper GS, Bichell DP, Rosborough DM, Sears SP, et al. Minimally invasive cardiac valve surgery improves patient satisfaction while reducing costs of cardiac valve replacement and repair. Ann Surg. 1997;226(4):421-8. https://doi.org/10.1097/00000658-199710000-00003.

3. Felger JE, Chitwood WR Jr, Nifong LW, Holbert D. Evolution of mitral valve surgery: toward a totally endoscopic approach. Ann Thorac Surg. 2001;72(4): 1203-9. https://doi.org/10.1016/S0003-4975(01)02978-2.

4. Walther T, Falk V, Metz S, Diegeler A, Battellini R, Autschbach R, et al. Pain and quality of life after minimally invasive versus conventional cardiac surgery. Ann Thorac Surg. 1999;67(6):1643-7. https://doi.org/10.1016/ S0003-4975(99)00284-2.

5. Lucà F, van Garsse L, Rao CM, et al. Minimally invasive mitral valve surgery: a systematic review. Minim Invasive Surg. 2013;2013:179569.

6. Modi P, Hassan A, Chitwood WR Jr. Minimally invasive mitral valve surgery: a systematic review and meta-analysis. Eur J Cardiothorac Surg. 2008;34(5): 943-52. https://doi.org/10.1016/j.ejcts.2008.07.057.

7. Wolfe JA, Malaisrie SC, Farivar RS, Khan JH, Hargrove WC, Moront MG, et al Minimally invasive mitral valve surgery II: surgical technique and postoperative management. Innovations (Phila). 2016;11(4):251-9. https:// doi.org/10.1097/imi.0000000000000300.

8. Casselman FP, Van Slycke S, Wellens F, et al. From classical sternotomy to truly endoscopic mitral valve surgery: a step by step procedure. Heart Lung Circ. 2003;12(3):172-7. https://doi.org/10.1046/j.1444-2892.2003.00209.x.

9. Ritwick B, Chaudhuri K, Crouch G, et al. Minimally Invasive Mitral Valve Procedures: The Current State. Minim Invasive Surg. 2013;2013:679276

10. Tarui T, Miyata K, Shigematsu S, Watanabe G. Risk factors to predict leg ischemia in patients undergoing single femoral artery cannulation in minimally invasive cardiac surgery. Perfusion. 2018;33(7):533-7. https://doi. org/10.1177/0267659118768151.

11. Huang LC, Chen DZ, Chen LW, Xu QC, Zheng ZH, Dai XF. Health-related quality of life following minimally invasive totally endoscopic mitral valve surgery. J Cardiothorac Surg. 2020;15(1):194 Published 2020 Jul 28.

12. Phillips SJ, Ballentine B, Slonine D, Hall J, Vandehaar J, Kongtahworn C, et al. Percutaneous initiation of cardiopulmonary bypass. Ann Thorac Surg. 1983; 36(2):223-5. https://doi.org/10.1016/S0003-4975(10)60462-6.

13. Jaski BE, Ortiz B, Alla KR, et al. A 20-year experience with urgent percutaneous cardiopulmonary bypass for salvage of potential survivors of refractory cardiovascular collapse. J Thorac Cardiovasc Surg. 2010;139(3): 753-7.e72.

14. Sagbas E, Caynak B, Duran C, Sen O, Kabakci B, Sanisoglu I, et al. Mid-term results of peripheric cannulation after port-access surgery. Interact Cardiovasc Thorac Surg. 2007;6(6):744-7. https://doi.org/10.1510/icvts.2007.1 62669.

15. Jackson KW, Timpa J, Mcllwain RB, et al. Side-arm grafts for femoral extracorporeal membrane oxygenation cannulation. Ann Thorac Surg. 2012; 94(5):e111-2. https://doi.org/10.1016/j.athoracsur.2012.05.064.
16. Marasco SF, Tutungi E, Vallance SA, et al. A Phase 1 study of a novel bidirectional perfusion cannula in patients undergoing femoral cannulation for cardiac surgery. Innovations (Phila).

17. SELDINGER SI. Catheter replacement of the needle in percutaneous arteriography; a new technique. Acta Radiol. 1953;39(5):368-76. https://doi. org/10.3109/00016925309136722

18. Sacco RL, Kasner SE, Broderick JP, Caplan LR, Connors JJ, Culebras A, et al. An updated definition of stroke for the 21st century: a statement for healthcare professionals from the American Heart Association/American Stroke Association. Stroke. 2013;44(7):2064-89. https://doi.org/10.1161/STR. Ob013e318296aeca.

19. Hankey GJ. Stroke. Lancet. 2017;389(10069):641-54. https://doi.org/10.1016/ S0140-6736(16)30962-X.

20. Khwaja A. KDIGO clinical practice guidelines for acute kidney injury. Nephron Clin Pract. 2012;120(4):c179-84. https://doi.org/10.1159/000339789.

21. Mohr FW, Falk V, Diegeler A, Walther T, van Son JA, Autschbach R. Minimally invasive port-access mitral valve surgery. J Thorac Cardiovasc Surg. 1998; 115(3):567-76. https://doi.org/10.1016/S0022-5223(98)70320-4.

22. Huang LC, Chen DZ, Chen LW, Xu QC, Zheng ZH, Dai XF. The use of the Scar Cosmesis Assessment and rating scale to evaluate the cosmetic outcomes of totally thoracoscopic cardiac surgery. J Cardiothorac Surg. 2020;15(1):250 Published 2020 Sep 11

23. Vanermen H, Wellens F, De Geest R, Degrieck I, Van Praet F. Video-assisted port-access mitral valve surgery: from debut to routine surgery. Will trocarport-access cardiac surgery ultimately lead to robotic cardiac surgery? Semin Thorac Cardiovasc Surg. 1999;11(3):223-34. https://doi.org/10.1016/S1 043-0679(99)70063-8.

24. Bedeir K, Reardon M, Ramchandani M, Singh K, Ramlawi B. Elevated stroke risk associated with femoral artery cannulation during mitral valve surgery. Semin Thorac Cardiovasc Surg. 2015;27(2):97-103. https://doi.org/10.1053/j. semtcvs.2015.06.008.

25. Chan EY, Lumbao DM, Iribarne A, Easterwood R, Yang JY, Cheema FH, et al. Evolution of cannulation techniques for minimally invasive cardiac surgery: a 10-year journey. Innovations (Phila). 2012;7(1):9-14. https://doi.org/10.1 097/imi.0b013e318253369a.

26. Crooke GA, Schwartz CF, Ribakove GH, Ursomanno P, Gogoladze G, Culliford AT, et al. Retrograde arterial perfusion, not incision location, significantly increases the risk of stroke in reoperative mitral valve procedures. Ann Thorac Surg. 2010;89(3):723-30. https://doi.org/10.1016/j.athoracsur.2009.11. 061.

27. Badhwar V. Are we going backwards or forwards in minimally invasive mitral valve surgery? Three eras of perfusion strategy. Semin Thorac Cardiovasc Surg. 2015;27(2):104-5. https://doi.org/10.1053/j.semtcvs.2015.09. 002.

28. Ward AF, Loulmet DF, Neuburger PJ, Grossi EA. Outcomes of peripheral perfusion with balloon aortic clamping for totally endoscopic robotic mitral valve repair. J Thorac Cardiovasc Surg. 2014;148(6):2769-72. https://doi.org/1 0.1016/j.jtcvs.2014.05.035.

29. Ad N, Holmes SD, Shuman DJ, Pritchard G, Massimiano PS. Minimally invasive mitral valve surgery without aortic cross-clamping and with femoral cannulation is not associated with increased risk of stroke compared with traditional mitral valve surgery: a propensity score-matched analysis. Eur J Cardiothorac Surg. 2015;48(6):868-72. https://doi.org/10.1093/ejcts/ezv017.

30. Murzi M, Kallushi E, Solinas M, Glauber M. Video-assisted right atrial surgery with a single two-stage femoral venous cannula. Interact Cardiovasc Thorac Surg. 2009;9(1):9-10. https://doi.org/10.1510/icvts.2008.201236.

31. Saadat S, Schultheis M, Azzolini A, Romero J, Dombrovskiy V, Odroniec K, et al. Femoral cannulation: a safe vascular access option for cardiopulmonary bypass in minimally invasive cardiac surgery. Perfusion. 2016;31(2):131-4. https://doi.org/10.1177/0267659115588631.

32. Moschovas A, Amorim PA, Nold M, Faerber G, Diab M, Buenger T, et al. Percutaneous cannulation for cardiopulmonary bypass in minimally invasive surgery is associated with reduced groin complications. Interact Cardiovasc Thorac Surg. 2017;25(3):377-83. https://doi.org/10.1093/icvts/ivx140.

33. Lamelas J, Aberle C, Macias AE, Alnajar A. Cannulation strategies for minimally invasive cardiac surgery. Innovations (Phila). 2020;15(3):261-9. https://doi.org/10.1177/1556984520911917.

\section{Publisher's Note}

Springer Nature remains neutral with regard to jurisdictional claims in published maps and institutional affiliations. 